\title{
2.5D/3D MODELS FOR THE ENHANCEMENT OF ARCHITECTURAL-URBAN HERITAGE. AN VIRTUAL TOUR OF DESIGN OF THE FASCIST HEADQUARTERS IN LITTORIA
}

\author{
E. Ippoliti ${ }^{\text {a }}$, M. Calvano ${ }^{\text {a }}$, L. Mores ${ }^{\text {b }}$, \\ a Dipartimento di Storia, Disegno e Restauro dell'Architettura, Sapienza Università di Roma, Piazza Borghese 9, 00186 \\ Roma - elena.ippoliti@uniroma1.it, architetto.calvano@gmail.com \\ b Sapienza Università di Roma, Piazza Borghese 9,00186 Roma - lorenzo.mores@gmail.com
}

\section{Commission}

KEY WORDS: ICT and Cultural Heritage, Virtual Tour, Panorama Photogrammetry, Cartography, 3D and 2.5D Modeling

\begin{abstract}
:
Enhancement of cultural heritage is not simply a matter of preserving material objects but comes full circle only when the heritage can be enjoyed and used by the community. This is the rationale behind this presentation: an urban Virtual Tour to explore the 1937 design of the Fascist Headquarters in Littoria, now part of Latina, by the architect Oriolo Frezzotti. Although the application is deliberately "simple", it was part of a much broader framework of goals.

One such goal was to create "friendly and perceptively meaningful" interfaces by integrating different "3D models" and so enriching. In fact, by exploiting the activation of natural mechanisms of visual perception and the ensuing emotional emphasis associated with vision, the illusionistic simulation of the scene facilitates access to the data even for "amateur" users.

A second goal was to "contextualise the information" on which the concept of cultural heritage is based. In the application, communication of the heritage is linked to its physical and linguistic context; the latter is then used as a basis from which to set out to explore and understand the historical evidence.

A third goal was to foster the widespread dissemination and sharing of this heritage of knowledge. On the one hand we worked to make the application usable from the Web, on the other, we established a reliable, rapid operational procedure with high quality processed data and ensuing contents. The procedure was also repeatable on a large scale.
\end{abstract}

\section{INTRODUCTION}

\subsection{Enhancement of Cultural Heritage}

Enhancement of cultural heritage is not simply a matter of preserving material objects but comes full circle only when the heritage can be enjoyed and used by the community. Indeed, we could say that all actions to preserve and safeguard the physical state of cultural heritage or increase our knowledge of that heritage is meaningful only if placed in a broader context, i.e., if it is made available to the community. Only then can cultural heritage fulfil its primary function as a vehicle to transmit culture, in other words that complex mix of knowledge, skills and values of a society at any given moment in time.

Enhancement has multiple, complex objectives, and these objectives were already specified in the final report by the Francheschini Commission (1967) which introduced the legal term "cultural asset" (now cultural heritage).

To all intents and purposes, this Report sparked a new and improved season of culture. For the first time, the focus shifted from aesthetic to historical values, and interest spread from individual monuments to the context; whether or not it was artistically important, cultural heritage now included all "material evidence with the value of civilisation".

This more inclusive definition of cultural heritage prompted a change of perspective: its focus and associated legal issues no longer concentrated on the physical nature of the material object, but on its cultural value. As a result, the concept of safeguard also changed to include all actions aimed at providing the community with greater and more tangible enjoyment of the cultural value represented by the heritage. The intrinsic reason behind the preservation of cultural heritage was to ensure its transmission to future generations. As active historical evidence, cultural heritage is a remarkable source of critical and scientific knowledge which can also provide active education. According to the Report, the purpose of enhancement becomes tangible only if the community is able to exercise its "rights" over cultural heritage. Amongst these rights, the right to information and the right to fruition; the former through immediate communication in ways best suited to scientific purposes and cultural knowledge, the latter in the most appropriate manner possible (Franceschini, 1967).

\subsection{ICT and Cultural Heritage}

Today, almost fifty years later, a much more widespread but nevertheless careful and appropriate use of digital technologies would significantly accelerate implementation of the measures laid down in the Report; it would also increase the opportunities and ways in which the community can exercise its right to information and fruition of cultural heritage.

In the last twenty years numerous studies have systematically and meticulously researched how to apply ICT to cultural heritage, and we should consider them in this light. In effect, they have prompted a reconsideration of the complex system of safeguard, management and enhancement.

These studies initially focused on the renovation of museums, libraries and archives which then extended their function from mere preservation to the production and promotion of culture. More recently, thanks to further progress in the development of spatial simulation and visualisation technologies, several applications have focused on studying and defining participative and immersive forms of communication which, if exploited properly, will undoubtedly provide enhanced access 
by the public to the contents of cultural heritage.Progress in the field of technologies and network connections have prompted important changes in communication and fruition models, and in the way we build knowledge (Ippoliti and Meschini, 2011).

The application presented here has exploited these developments and by integrating and superimposing real and virtual space has de facto broadened the notion of "representation/3D digital model" to that of a "3D digital scene".

The "3D digital scene" is the heart and soul of the application the creation of an urban Virtual Tour to explore the 1937 design by the architect Oriolo Frezzotti of the Fascist Headquarters in the city of Littoria, now part of Latina: it is considered as the ultimate "participated" site in which full access is provided to cultural contents and the construction of information. In fact, the approach to cultural heritage in the " $3 \mathrm{D}$ digital scene" is based on emotional and sensorial involvement which materialises chiefly through predominantly visual communicative models, and facilitates involvement and participation through experience.

Although the application presented here is deliberately "simple", it was part of a much broader and more general framework of goals.

One goal was to experiment with "friendly and perceptively meaningful" interfaces in order to increase the individual's levels of interaction with the cultural heritage thanks to spatial exploration. The goal was to "create" a predominantly visual cultural heritage communication mode by integrating different "3D models". In fact, the illusionistic simulation of the scene facilitates access to information even by "amateur" users; this is achieved by exploiting the activation of natural visual perception mechanisms and the ensuing emotional emphasis associated with vision (Ippoliti and Meschini, 2010).

A second goal, linked directly to the first, was to "contextualise the data" according to the concept of cultural heritage based on the relationship between object and context. In the application, communication of the heritage taken as a case study is linked to its physical and linguistic context; this context is used as a basis from which to set out to explore and understand this historical evidence (Ippoliti et al, 2012).

A third goal was to foster the widespread dissemination and sharing of this heritage of knowledge. We initially envisaged fruition of the application from the web and at the same time verified the potential of low-cost and easy-to-use systems and tools, whenever possible open source. We wanted to identify "operational procedures" which could be implemented in so-tospeak "extreme" conditions (using very little economic resources), but ones which were nevertheless reliable vis-à-vis the quality of the processed data, also in accordance with the Charter of London (Denard, 2009).

\section{THE APPLICATION}

\subsection{ICT and architectural-urban Heritage: why we chose this case study}

When considering how to apply ICT to cultural heritage, special attention must be paid to architectural heritage and urban space which the former help to create as part of the system.

If these experiments are to focus on the right to knowledge, fruition, and enjoyment of this heritage by as many people as possible, then the way in which these goals are pursued must correspond to the key "intentions" behind the creation of these assets, i.e., the intentions of their "authors" (including the clients, designers, workmen, etc.)
Although the possible "intentions" behind an architectural object, and even more so of an urban space, are undoubtedly endless, they can be traced back, albeit schematically, to the Vitruvian concepts of "firmitatis, utilitatis, venustatis", in which the latter is the extreme synthesis of the first two.

It is easy, therefore, to understand that architectural and urban heritage should be considered, first and foremost, as signs and communicative artefacts, in other words the meaning of an architectural work or urban space can only be understood if it is proposed according to the primary "intention" for which it was created: to be interpreted based on the processes associated with the sensory stimuli of visual perception (Antinucci, 2004).

The features that help make these assets "evidence with the value of civilisation" are primarily visual features, in other words, linked to their appearance. This means that to be coherently enjoyed they have to be considered as signs, i.e., through relevant communicative contexts and forms.

This is the rationale behind our choice of case study for this application: the 1937 design by Oriolo Frezzotti of the Fascist Headquarters in Littoria. We deliberately chose a unique topic so that its obvious communicative intent would turn the application into a paradigmatic example.

A paradigmatic example chiefly because it involves the design of Fascist Headquarters. This building type, specifically designed as the symbol of its client, the Fascist party, was later turned into an eloquent and visible representation of all the models and values of that period. The main task of the building was to communicate, and this was achieved by creating architectural stylistic elements appropriate and functional to the message (Mangione and Soffitta, 2006).

Another reason why we chose this design project was the city in which the Fascist Headquarters was built. Littoria, now Latina, was founded in 1932 to service the rural development which had begun with the reclamation of the Pontine Marshes. A foundation city which Oriolo Frezzotti, tasked with its design, intended to symbolically crystallise by making generous use of simple dynamic geometries; he imagined a city with an octagonal nucleus from which radial axes with solid and empty spaces departed and were joined by concentric polygons which gradually expanded to organically connect the centre to the outlying hamlets (Cefaly, 1984; Galeazzi and Muratore, 1999). The echo of this event in the foreign media, rather than the region's immediate needs, persuaded the regime to use Littoria as a propaganda tool. In 1934 the status of the city was changed from a rural hamlet to a provincial capital and used as the ideal setting for the numerous visits Mussolini made to the city from that moment on.

The rapid change in its status and political importance sparked a stream of urban plans and designs for public buildings (although often not sufficiently pondered) to try and adapt the city to its new symbolic functions. The short space of time that elapsed between its foundation and the fall of the regime (1943) made it impossible to implement most of these designs, or consolidate the ones which had been built so that they could become the genetic heritage of the city's urban memory.

The numerous processes and designs, which never got off the drawing board and never became part of the built, did however gradually contribute to writing its history and consolidating an imaginary forma urbis which is much more representative and metaphorical than the real layout.

This is the last and perhaps the most important reason for our choice: evidence with the value of civilisation, i.e., cultural heritage, should certainly not be preserved only because it has a material form. What we need to preserve here is the history that can be traced and recreated based on a design illustrated in a few pencil drawings by Oriolo Frezzotti (and these do 
absolutely need to be preserved). In their current state these drawings can communicate the author's intentions only to very few people, i.e., experts in this field. Yet if this cultural heritage is to be truly enjoyed and exploited by the public at large it has to be "built" - albeit virtually - and simulate the forms for which it was designed. Only by reproducing the illusion of those scenes will the cultural heritage be able to "communicate" to the "amateur" user; using perceptive mechanisms, these scenes will spark emotions in the observer, empathically activate participation in the communicative process, and thereby convey knowledge.

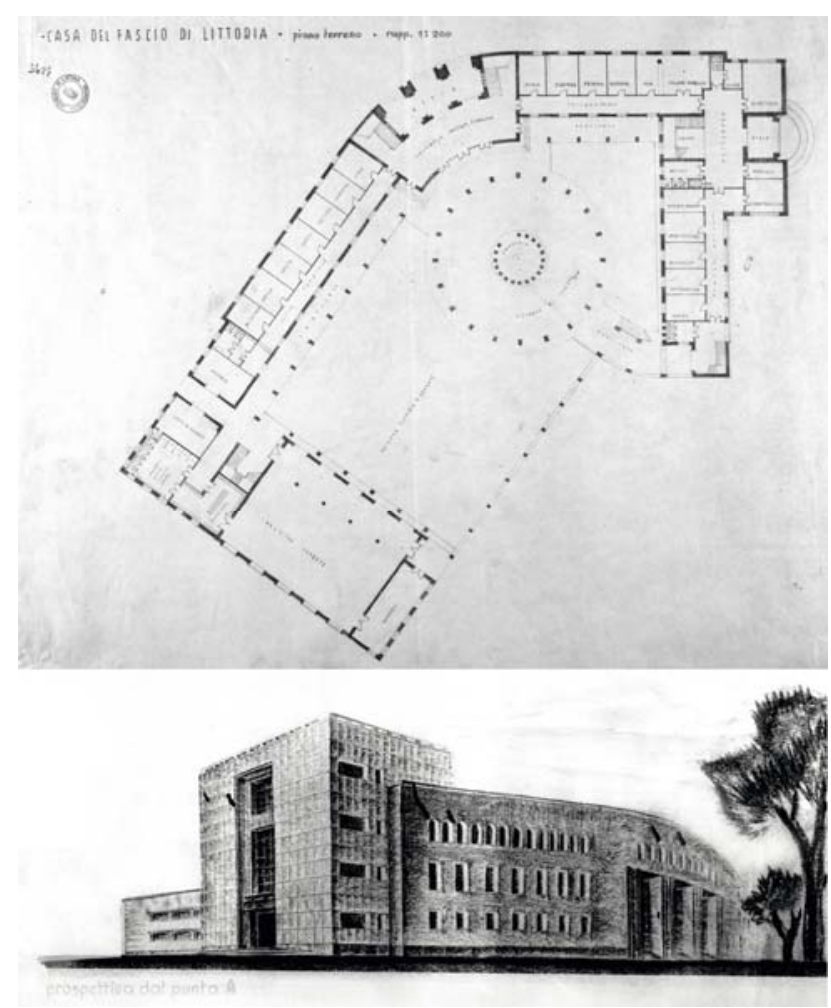

Figures 1-2. The design drawings of Fascist Headquarters

\subsection{Creating the Application}

Creating the application involved two separate but closely interlinked phases.

The first was the construction of the 3D digital model based on the most accurate and meticulous data possible regarding geometry, form, measurements and material quality. The second phase focused on creating the urban Virtual Tour, i.e., navigable, panoramic $2.5 \mathrm{D}$ representations.

\subsection{The 3D digital model. The geometries of the volumetric model}

The first phase involving the construction of the 3D digital model of the Fascist Headquarters was the hub around which the application was created. As mentioned earlier, we focused in particular on the accuracy and quality of the geometric and material data, as well as form and measurements; we wanted to create the most reliable hypothetical "reconstructed" design, i.e., the author's "intentions".

To achieve our goal we needed to take certain precautions given the quality of the original material. We should point out that it was a very preliminary design, created in a short space of time during which Frezzotti was also involved not only in drafting the master plan of the city, but also in designing and constructing several public buildings. In fact, the project is illustrated in just seven tables, four plans and two elevations and sections, all on a 1:200 scale. The seventh table contains the general plan (1:500) with the space occupied by the building and one perspective view (figures 1-2).

In addition we used "outdated" scansions with optical deformations (the original material was also deformed), and with old severely deteriorated copies.

After importing the raster material in a parametric modeller software, we began by making the materials geometrically coherent. We changed the scale of the tables to $1: 1$ in order to work in digital space with real measurements and be able to analyse and compare plans, elevations and sections; it was then possible to identify the main geometric, compositional and structural generatrices behind the project (figure 3). Vector tracing of the geometric patterns allowed us to control the deformations; above all it allowed us to identify the 3D geometric reference grid used to position and align the various elements on different horizontal and vertical planes.

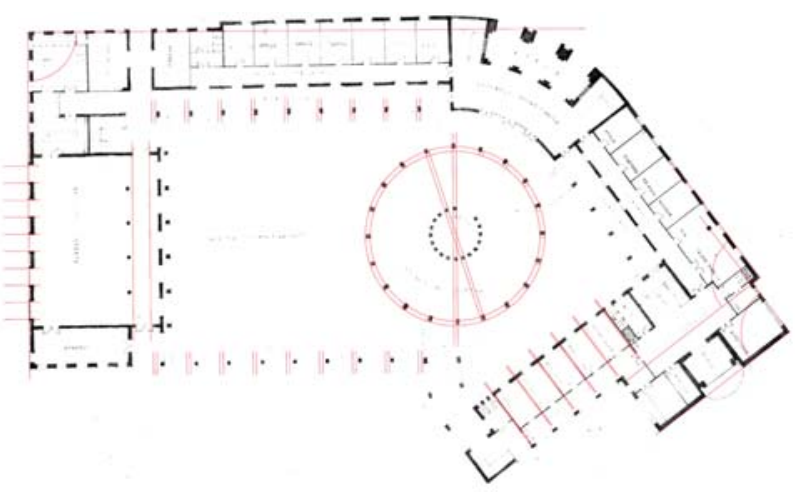

Figure 3. Layout of geometric patterns

Level by level the patterns identified in the various plans were "stacked" at their respective heights. We then checked the internal and external alignments at each floor level; when this check turned in positive results we were able to build several portions of the model in a continuous manner from the bottom up (figures 4-5).

Since the design was drawn on a 1:200 scale, we did not have enough data to be able to elaborate a "significantly perceptive" architectural model. So we decided to proceed using a series of typological, compositional and linguistic comparisons.

We started by analysing the designs and buildings of other Fascist Headquarters and immediately realised that no consistent types or styles existed despite the guidelines of the Regime and extensive production (an estimated 25,000 designs and 5,000 actual constructions over a twenty year period).

We then focused on the work of the architect Frezzotti to get a better understanding of his language and style. A critical assessment of several of his works, all built in Latina in 1934 (Finance Administration, Courthouse, Headquarters of the Banca d'Italia, Government Offices), showed that he used unique compositional elements: giant colonnades, porticoes, vertical tripartite division of the façade, double columns, fullheight windows, entrances crowned with balconies and arched openings. We then used these elements as reference material when building the model.

Having established the geometric, compositional and linguistic reference elements we focused on the digital modelling and adopted a procedure similar to the one governing design stages, 

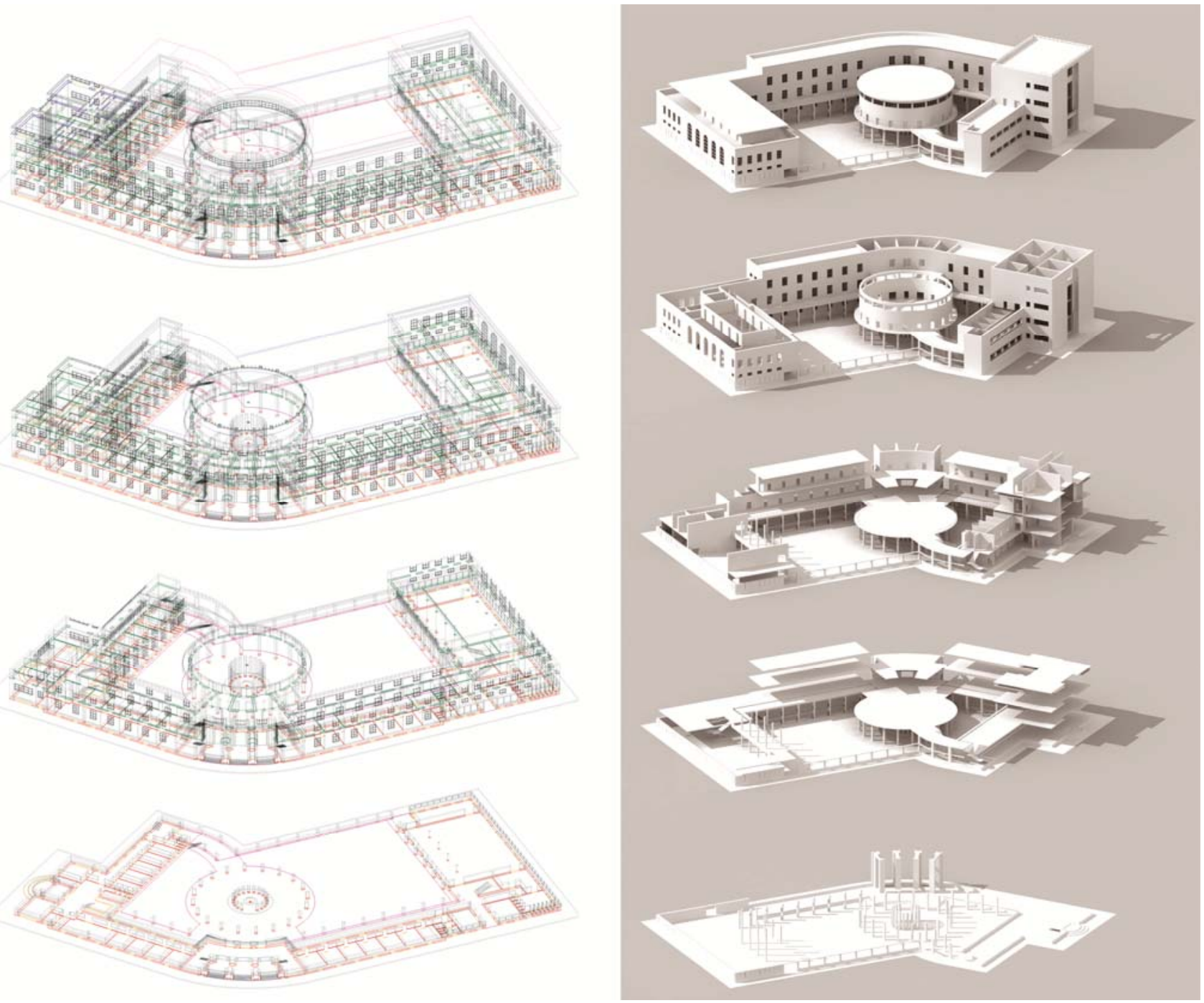

Figures 4-5. The procedure to building models
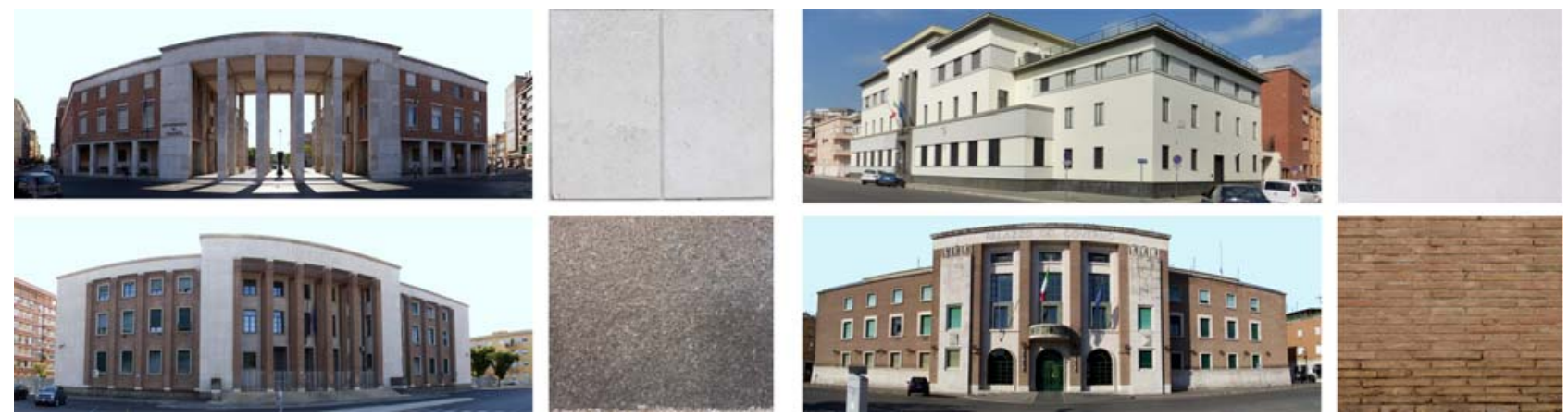

Figure 6. The Buildings by design Frezzotti in Latina. Analysis and critical comparison

from ideation to execution; we first juxtaposed the main primitive solids and then included the details.

We began by focusing on the external envelope and building all the volumes of the outer walls: we then moved on to the internal partition walls. Proceeding as if on a worksite, we began digital modelling, based on the raster, by drawing the fixed lines of the volumes using 'curves' arranged on the horizontal planes. Using special tools we arranged the walls (closed polysurfaces) on the curves using widths and heights gleaned from the plans and raster sections correctly oriented in the work space. Only then did we model the façade elements, integrating the data from the raster of the elevations to what had already been modelled.

Again using the plans, level by level, we drew the space occupied by the doors and windows which we then subtracted from the internal and external walls to create the openings. Once the parts structuring the shape of the model had been built, we then focused on the details - thresholds, windows and 
cornices - until we created the typical narrative style of a rationalist architectural model largely based on the juxtaposition of volumes and full and empty spaces.

Finally, repetitive elements were arranged using nested 3D blocks: for example, we built the window element and nested the fixed frame, the mobile frame, and the cornices of the opening. The block was repeated for each opening creating a coordinated family of one element.

\subsection{The 3D digital model. The realistic model: the materials}

Furthermore, we needed to integrate available data with regard to the treatment of the surface of the model and performance of the façade materials.

We analysed the graphics Frezzotti used in some of his drawings of designs built during that period in Latina and developed a "graphic code" of the materials. Then by analysing the buildings we had already used as reference to elaborate the volumetric model we obtained the materials he normally used (travertine, Roman peperino, plaster, face brick), the ones we believed fitted best with the Fascist Headquarters. The materials, in line with the architecture of that twenty-year period in Latina, were the result of a cross between the original prevalently rural local architectures, and the architectures of the regime with their giant and rigid stereometric forms. The former appeared coloured due to the use of materials such as face brick and plaster, while the latter often had peperino bases and were almost always covered in travertine slabs (figure 6). A careful photographic campaign of the materials in sample buildings and the ensuing treatment of the images with photo retouching software allowed us to create the texture samples we then used during rendering of the realistic model (figures 7-8).

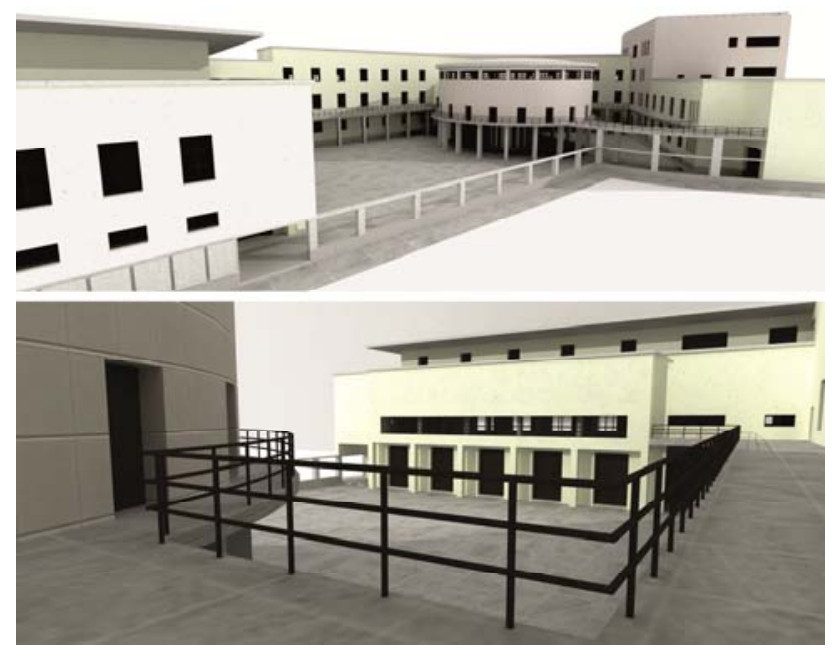

Figures 7-8. The realistic model

\subsection{The 2.5D digital model. The Virtual Tour}

The last phase of the application focused on creating a Virtual Tour of the city, i.e., panoramic $2.5 \mathrm{D}$ representations accessible from the web. The application had to provide a fluid exploration of the digital reconstruction of the Fascist Headquarters design inserted in the current context of the city of Latina.

Today the market provides numerous easy-to-use software programmes dedicated to the "automatic" mosaics of photographic images (photo stitching). Recent studies have shown that these programmes are particularly reliable, precise and accurate even when the photographs are taken with digital 'consumer' cameras. If care is taken, these photographs can provide reliable quality products of the representations and measurements (Shum and Szeliski 1997; Shum and Szeliski, 20001; Fangi, 2006; Fangi 2007; Wahbeh, 2011).

These studies have experimentally shown that the software are in fact sophisticated programmes for the algorithms of calculation used in orientation and, therefore, that the manual and/or automatic stitching operations are extremely reliable. The studies also show that the projective operations are just as reliable, since they refer in full to the principles of cartographic science, and in particular the problems associated with the projection of a sphere on a 2D surface.

Although the software used to create a $360^{\circ}$ panorama or virtual tour tend to vary, they all use a standard procedure with the following main stages: a $360^{\circ}$ photograph taken from a single station, the elaboration of the spherical photomosaic (i.e., reprojection of the photographs on a spherical surface), the generation (or rendering) of the panoramic image (i.e., representation of the spherical photomosaic on a $2 \mathrm{D}$ surface), and finally post-production operations to create the product (the navigable panorama, the interface, the sensitive areas on which to hang the other multimedia contents - texts, images, audio and video files, url addresses, etc.).

Once a photograph has been taken from a single station (central shooting position) with frames that have sufficient superimposition and the same focal length (Fangi, 2006); with photo stitching softwares The solving of the orientations is executed with a few simple commands.

By exploiting the identity ratio between the photographic image and the central projection, the internal orientation is solved because we know the focal distance of each frame, equal to the principal distance. We can then replace the single frame compared to the centre of projection at the time of shooting, i.e., recreate the perspective system of each frame.

Then the replace of the photographic images in space, each according to its own and relative position at the moment it was shot, is "typically" achieved by identifying similar image points in the photograph thanks to the superimposition of consecutive photographic shots and the central shooting position used for all the frames.

In the case of $360^{\circ}$ shots, the form itself of the photograph (i.e., achieved using a closed plot) provides greater control over the quality of the results of the orientations (Fangi, 2006). Finally, apart from spatially repositioning the single frames in their original position, each frame is projected from the central shooting position onto the surface of a sphere with a radius equal to the focal length, thereby creating a spherical photomosaic, i.e., performing the stitching (figure 9).
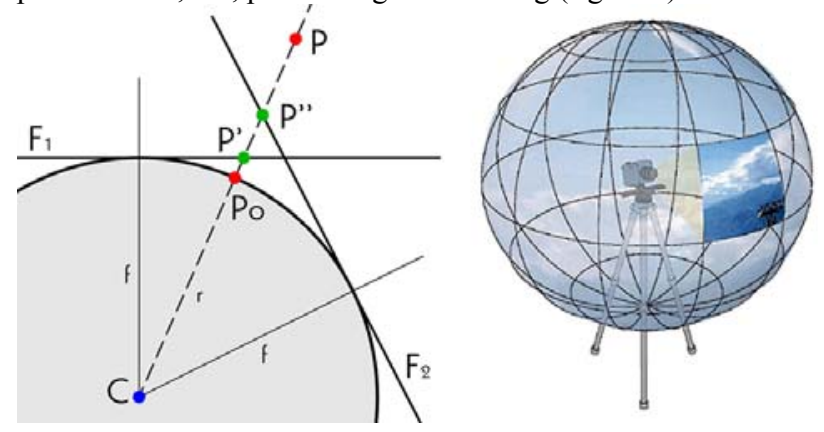

Figure 9. Projective relations from the center of sphere $\mathrm{C}$ between the object $(\mathrm{P})$, the photographs $\left(\mathrm{P}^{\prime}, \mathrm{P}^{\prime \prime}\right)$ and the projection on sphere (Po). Re-elaboration by Fangi (2006) 
Having solved the orientations, and having assessed their quality by measuring variance, we can create the panoramic image, often called a rendering which in this case has a broader meaning and refers to the graphic performance process, i.e., generation of an image. This phase is also used in the field of cartography; in fact it involves representing the surface of the sphere (in which the space covered by the photographs has already been reprojected) on a $2 \mathrm{D}$ surface.

The most commonly available rendering options are the ones known as cylindrical (figure 10), equirectangular (also called spherical, figure 11), rectilinear (also called snapshot) and cubic (figure 12); the latter are considered special applications and extensions of rectilinear projections.
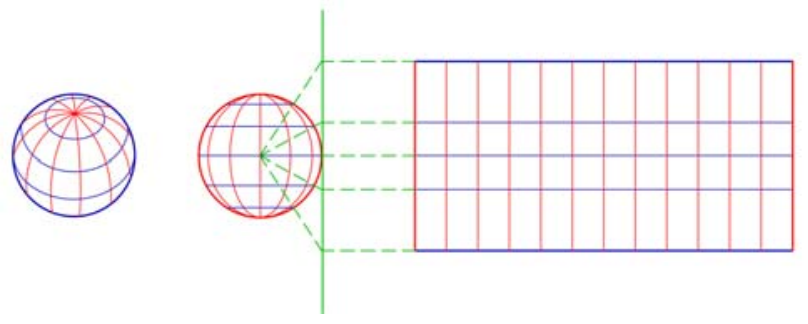

Figure 10. Cylindrical projection. Pattern
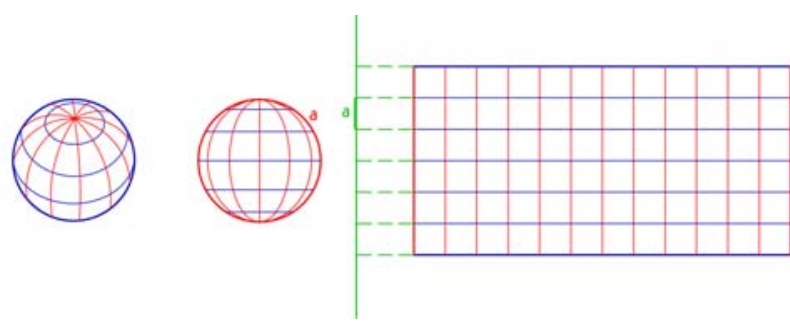

Figure 11. Equirectangular projection. Pattern

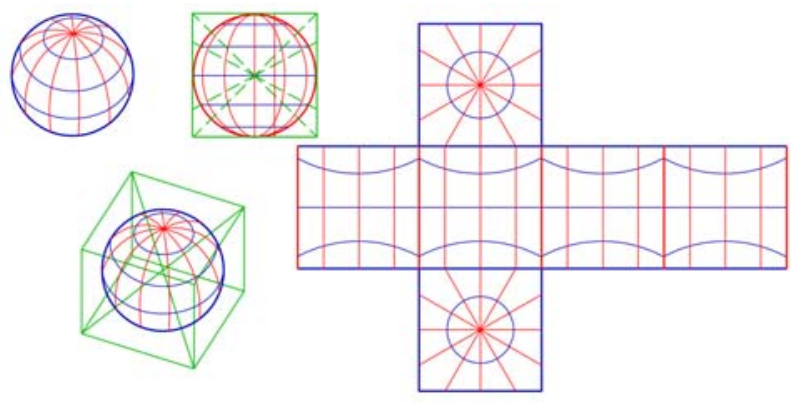

Figure 11. Cubic projection. Pattern

In particular, in these software programmes, equirectangular or spherical projection (the projection chosen to create the application) is considered a cartographic representation obtained by transposing points of the sphere onto a straight cylindrical surface imagined to be tangent to the sphere at its greatest parallel. It should be remembered that every point Po on the spherical surface, already a projection of real point $\mathrm{P}$ on the sphere, is identified, compared to the centre of the sphere, by a pair of coordinates representing the longitude and latitude of point Po, i.e., respectively the extension in degrees of the parallel arc passing through Po and falling between this point and the reference meridian, and the extension in degrees of the arc of meridian passing through Po and falling between this point and the maximum circumference (the greatest parallel or equator).
Every point Po on the spherical surface is therefore represented by the two-dimensional cartographic surface of the longitude and latitude, i.e., by the pair of coordinates $x=R \theta$ e $y=R \varphi$, where $\mathrm{R}$ is equal to the radius of the sphere, and the angles expressed in radians, which express the angle of azimuthal and vertical direction of point Po as if it were delimited by the centre of the sphere itself (figure 13).

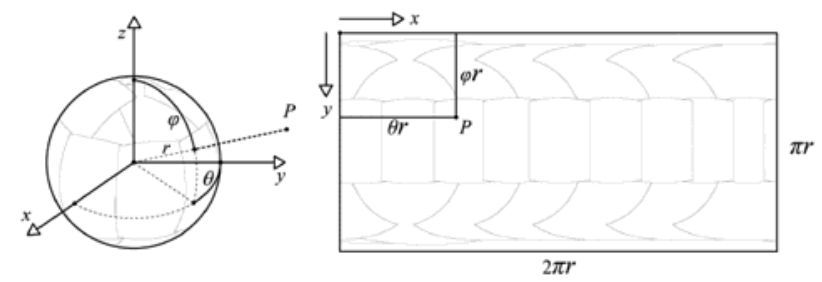

Figure 13. Point coordinates in an equirectangular projection

This representation, neither conform nor equivalent, is also called non projection insofar as it involves the simple transposition of polar coordinates to Cartesian coordinates. In this representation, the meridians and the parallels are all developed along lines - vertical and horizontal, parallel and equidistant and all the same length - and form a straight grid. As mentioned earlier, this application was meant to be used to create a continuous sequence of panoramas which would allow fluid exploration of the reconstructed design using modelling inserted in the existing photographically reproduced context. To begin with we needed to choose how many "viewpoints" were necessary to create a fluid route, and where they should be best positioned. Then we took the measurements carefully so that the "real" shots of the current urban context could be superimposed accurately on the "virtual" panoramic images of the reconstructed model, i.e., the panoramas were respectively and correctly oriented.

To do this we shot the $360^{\circ}$ photographic image of the urban environment using a panoramic head and a fisheye lens on a tripod. During this procedure we managed to establish the central shooting position by using several horizontal triangular grids and measuring the sides of the grids compared to the corners of the specially selected buildings.

We then used the cartographic base of the Urban Map of Latina, to which the digital model had already been correctly referred, and identified the coordinates of the positions of the projections of the centres of the panoramas on the $2 \mathrm{D}$ vector plane. Using the trilateration method we graphically drew the measurements taken during the campaign, starting with the corners of the known buildings represented in the map.

The achieved accuracy was in the range of $1 \mathrm{~cm}$ that was allowed with the recurrence of trilaterations. Anyway, the insufficient precision of the coordinates could produce only a defect of positioning of the model believed compatible with the scale of the Urban Map of Latina. But above all, this accuracy is coherent with the main goal of application that is the documentation for the enhancement of cultural heritage.

We went on to create six pairs of equirectangular representations, respectively of the existing urban environment and of the digital model of the Fascist Headquarters. For the former we used a photo stitching software, while the latter was developed using a parametric modeller working with a rendering engine after having positioned the camera with the fisheye lens in the established station points.

The six pairs of equirectangular representations were then imported into the raster graphic software and superimposed two by two (figure 14). The ensuing images, which were still 
equirectangular representations, were then imported into the Easypano Tourweaver ${ }^{\circledR}$ software to produce the visitable and interactive urban Virtual Tour collating six different panoramas in a single application. The latter can be accessed using the six interconnected hot spots which are linkable using a small map
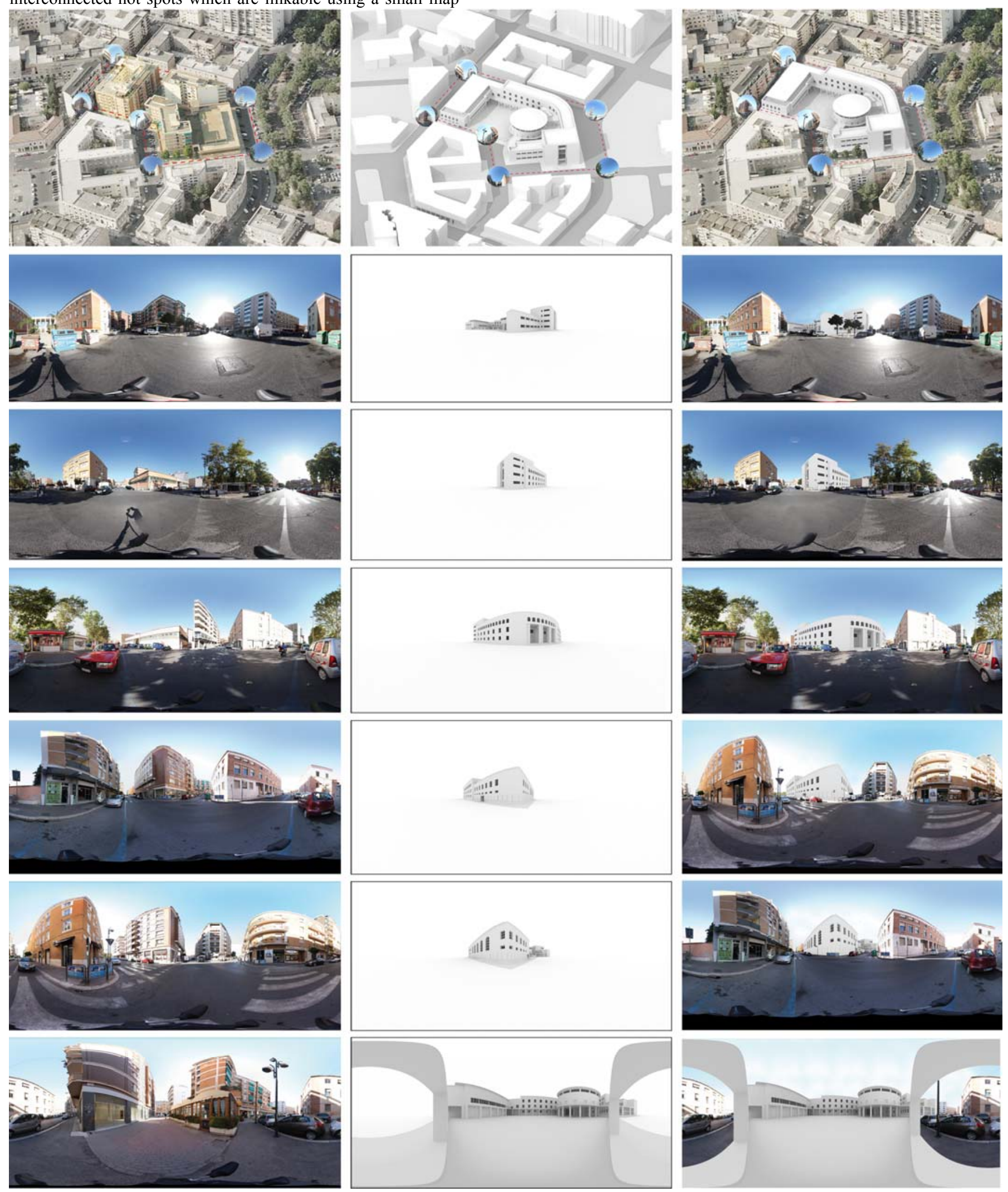

Figure 14. The procedure to Virtual Tour 


\section{CONCLUSIONS}

This application is an example of an operational procedure reproducible on a large scale insofar as it is rapid, easy to use, produces reliable quality data, and can be inexpensively implemented. The key element of this procedure is the " $3 \mathrm{D}$ digital scene" used as a tool to improve the quality of cultural heritage communication. By reproducing the illusion, the 3D digital scene turns the cultural heritage into a communicative artefact even for "amateur" users and enhances involvement and participation by using approaches based on emotional and sensorial involvement.

This idea could be successfully used to trigger the enhancement of architectural and urban heritage, especially so-called "minor" heritage which, at least numerically, makes up a large part of Italy's historical and environmental heritage.

It is however necessary that this type of applications for the digital heritage visualisation is rigorous as longer established cultural heritage research and communication methods.

To this goal, first the reconstruction of the 1937 design by Oriolo Frezzotti of the Fascist Headquarters in Littoria was based on results of a careful historical research conducted through literature sources and archives - texts and drawings.

Secondly, we have used photo-stitching software programmes that recent studies have shown that are particularly reliable, precise and accurate even when the photographs are taken with digital 'consumer' cameras. If care is taken, these software programmes can provide reliable quality products of the representations and measurements.

\section{REFERENCES}

Antinucci, F. 2004. Comunicare nel museo. GLF editori Laterza, Roma.

Apollonio, F. I., Gaiani, M., Fallavollita, F., et alii, 2013. Bologna porticoes project: A 3D repository for WHL UNESCO nomination. In: Digital Heritage International Congress (DigitalHeritage), 2013 , vol.1, no., pp.563-570.

Calvano, M., Wahbeh W., 2014. Disegnare la Memoria. L'immagine della città attraverso la rappresentazione integrata Drawing the Memory. The image of the city through the integrated representation. In: DISEGNARECON, vol. 7, n. 13, 2014, p. 1-12. http://disegnarecon.unibo.it/ article/view/ $4102 / 3774$

Cefaly, P., 1984. Littoria 1932-1942: gli architetti e la citta. CLEAR, Latina.

Centofanti, M., Brusaporci S., Lucchese, V., 2014. Architectural Heritage and 3D Models. In: Di Giamberardino, P. et al. (eds), Computational Modeling of Objects Presented in Images. Lecture Notes in Computational Vision and Biomechanics, Volume 15, Springer International Publishing, pp 31-49.

Denard, H., (editor), 2009. The London Charter for the Computer-based Visualisation of Cultural Heritage. http://www.londoncharter.org/fileadmin/templates/main/docs/lo ndon_charter_2_1_en.pdf

Fangi, G., 2006. Investigation on the suitability of the spherical panoramas by Realviz Stitcher for metric purposes. In: ISPRS Archives, Volume XXXVI Part 5, 2006. Proceedings of the ISPRS Commission V Symposium 'Image Engineering and
Vision Metrology', September 25-27, 2006, Dresden, Germany, Editor(s): H.-G. Maas, D. Schneider http://www.isprs.org/ proceedings/XXXVI/part5/paper/1222_Dresden06.pdf

Fangi, G., 2007. The Multi-image spherical Panoramas as a tool for Architectural Survey. In: ISPRS Archives, Volume XXXVI5/C53, 2007. Proceedings of the 21st CIPA symposium 'AntiCIPAting the future of the cultural past', October 1-6, 2007, Athens, Greece. http://www.isprs.org/ proceedings/XXXVI/5-C53/papers/FP061.pdf

Franceschini, F., 1967. Atti della Commissione Franceschini. http://archivi.beniculturali.it/Biblioteca/Studi/franceschini.pdf

Galeazzi, C., Muratore, G., 1999. Littoria Latina: la storia, le architetture. Novecento, Latina.

Ippoliti E., Meschini A., 2010. Dal "modello 3D" alla "scena 3D". Prospettive e opportunità per la valorizzazione del patrimonio culturale architettonico e urbano - From the "3D model" to the "3D scene". Prospects and opportunities for the enhancement of an architectural and urban cultural heritage. In: DISEGNARECON, vol. 3, n. 6, 2010, p. 77-91. http://disegnarecon.unibo.it/article/view/2083/1470

Ippoliti E., Meschini A., 2011 (editor). Tecnologie per la comunicazione del patrimonio culturale. Cultural Heritage communication technology. DISEGNARECON. vol.4, n. 8, pp. 1-138. http://disegnarecon.unibo.it/issue/view/276

Ippoliti E., Meschini A., Moscati A., Rossi D., De Luca L., 2012. Shedding Light on the City: Discovering, Appreciating and Sharing Cultural Heritage using 3D Visual Technology. In: 18th International Conference on Virtual Systems and Multimedia (VSMM), Proceedings, 2 - 5 September 2012, Milan, Italy, IEEE, pp. 141-148.

Ippoliti E., 2013. Valorizzare il patrimonio culturale: esperienze per Ascoli Piceno - Shedding light on the Cultural Heritage: the Ascoli Piceno experience. Aracne, Roma: 2013.

Luhmann, T., 2004. A Historical Review on Panorama Photogrammetry. In: ISPRS Archives, Volume XXXIV-5/W16, 2004. Panoramic Photogrammetry Workshop, 19-22 February 2004, Dresden, Germany. Editor(s): H.-G. Maas, D. Schneider, http://www.isprs.org/proceedings/XXXIV/5-W16/papers/ PanoWS_Dresden2004_Luhmann_a.pdf

Mangione, F., Soffitta, A., 2006. L'Architettura delle Case del Fascio nella Regione Lazio. Alinea, Firenze.

Shum H. Y., Szeliski R., 1997. Creating full view panoramic image mosaics and environment maps. In Computer Graphics, SIGGRAPH '97 Proceedings, , pp 251-258. Also in http://research.microsoft.com/apps/pubs/default.aspx?id=75673

Shum H. Y., Szeliski R., 2000. Systems and Experiment Paper: Construction of Panoramic Image Mosaics with Global and Local Alignment. In International Journal of Computer Vision, February 2000, Volume 36, Issue 2, pp 101-130. Also in http://research.microsoft.com/apps/pubs/default.aspx?id=75614

Wahbeh, W., 2011. Architectural Digital Photogrammetry. Panoramic Image-Based Interactive Modelling. PHD Thesis, dicembre 2011. Tutor prof. Leonardo Paris. La Sapienza Università di Roma, Dipartimento di Storia, Disegno e Restauro dell'Architettura. http://padis.uniroma1.it/handle/10805/1253 